\title{
U- and Th-isotopes in an Estuarine System in Southwest Spain: Tidal and Seasonal Variations
}

\author{
R. PERIÁÑEZ1', A. MARTÍNEZ-AGUIRRE ${ }^{1}$ and M. GARCíA-LEÓN ${ }^{2}$ \\ 'Dpto Física Aplicada, E.U. Ingeniería Técnica Agrícola, Universidad de Sevilla, Ctra Utrera Km 1, \\ 41071, Sevilla, Spain and 'Dpto Física Atómica Molecular y Nuclear, Universidad de Sevilla, \\ Apdo 1065,41080 , Sevilla, Spain
}

\begin{abstract}
The presence of $\mathrm{U}$ - and Th-isotopes in suspended matter from an estuarine system which surrounds a phosphate fertilizer processing complex has been investigated. A clear radioactive impact from the complex has been confirmed since up to 86 and $116 \mu \mathrm{g} / \mathrm{g}$ of $\mathrm{U}$ and $\mathrm{Th}$ respectively have been detected. The effect of tides and seasonal conditions, temperature and salinity, on the results has also been investigated. Some distribution coefficients are given. Copyright (C) 1996. Elsevier Science Ltd
\end{abstract}

\section{Introduction}

The Odiel river is located in the southwest of Spain and discharges its waters to the Atlantic Ocean. In the lower reaches, it forms an estuarine tidal system which surrounds a large industrial area where a phosphate fertilizer complex is located. This complex releases part of its wastes directly into the Odiel river.

It is well known that such wastes contain significant amounts of natural radionuclides: $\mathrm{Ra}, \mathrm{U}$-, Th-isotopes and their daughters. The presence of Ra-isotopes in water and suspended matter samples collected from the Odiel river has already been studied (Periáñez and García-León, 1993; Periáñez et al., 1994). These studies have revealed that a clear radioactive impact is being produced by the fertilizer complex since, for instance, up to $670 \mathrm{mBq} / \mathrm{L}$ of ${ }^{226} \mathrm{Ra}$ have been detected in a water sample collected close to the complex.

Although there are some data on the $U$ - and Th-isotopes content in the Odiel river suspended matter (Martínez-Aguirre et al., 1994), a more detailed study is carried out. The objective of this work is to achieve a complete understanding of the distribution of $U$ and $T h$ in suspended matter in the Odiel river, including the effect of tidal and seasonal conditions on the radionuclide concentrations. This information, together with some $K_{d}$ distribution coefficients which have also been measured, will be necessary to complete some modelling works on the dispersion of radionuclides in aquatic tidal systems (including the transfers between solid and liquid phases) which are being carried out by our group.

The next section describes the sampling work as well as the isotope determination methods. In following sections the results are presented and discussed.

\section{Experimental}

Samples of river water were collected along the Odiel river basin (see Fig. 1) during July 1990 (dry season) and March 1991 (wet season) to study the influence of seasonal conditions on the $U$ and Th concentrations. Water samples were collected in plastic bottles. Two samples were taken from each sampling station: one during high water and the other during low water to study the influence of tidal oscillations. The water was filtered as soon as possible through previously weighed Nuclepore filters, $0.4 \mu \mathrm{m}$ pore size, so as to separate the suspended matter. The filter was then dried and weighed to calculate the mass of recovered matter. After this, the filter was covered with $\mathrm{HCl}$ and placed into an ultrasonic bath for some half an hour during which time the suspended matter is separated from the filter and dissolved. The filter was then washed with $\mathrm{HNO}_{3}$ which is added to the $\mathrm{HCl}$ to form aqua regia. This solution is heated slowly to dissolve all remaining particles. After cooling, ${ }^{232} \mathrm{U}$ and ${ }^{229} \mathrm{Th}$ spikes and some $\mathrm{Fe}$ carrier were added to the solution. Precipitation of $\mathrm{Fe}$ with oxyhydroxides with concentrated amonium hydroxide follows.

$\mathrm{U}$ - and Th-isotopes were extracted from the precipitate using anion exchange resins (DOWEX AG 1X8, $\mathrm{HCl}$ form) and electroplated onto stainless steel planchets. Activities were measured by $\mathrm{Si}$ ion-implanted detector alpha spectrometry. More 


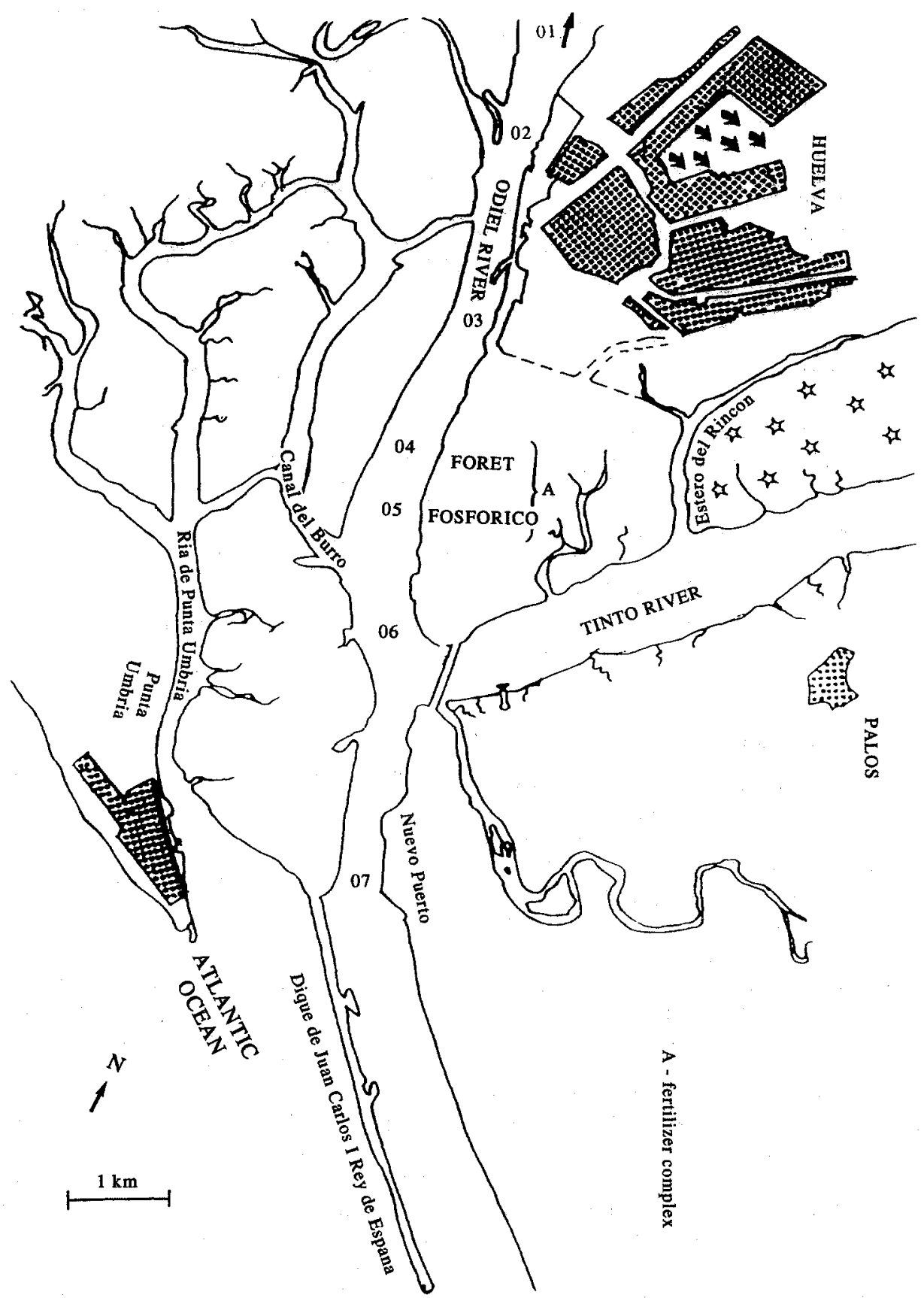

Fig. 1. Map of the Odiel river showing the sampling stations.

details of the radiochemical and measurement methods can be found in Martínez-Aguirre (1991).

\section{Results and Discussion}

In what follows, the samples are denoted by ' $O$ ' (Odiel). The numbers given to each sample identify the sampling station (see Fig. 1), which are distributed along the lower reaches of the river, close to the fertilizer complex. Station 1 is, however, far upstream of this area near the river source. As it is not supposed to be affected by tidal oscillations, only one sample was collected there.

Tables 1 and 2 present the results obtained for the samples collected in 1990, for low and high water respectively. These give the $\mathrm{U}$ and $\mathrm{Th}$ concentrations in suspended matter in $\mu \mathrm{g} / \mathrm{g}$ and some interesting activity ratios. In the case of the low water samples, there is a high concentration peak in station 04 , for both $\mathrm{U}$ and $\mathrm{Th}$, revealing the presence of a local source of activity. Up to 86 and $116 \mu \mathrm{g} / \mathrm{g}$ of $U$ and Th respectively have been detected in this sample, 
Table 1. Concentrations of $U$ and $T h$ in $\mu \mathrm{g} / \mathrm{g}$ for the suspended matter samples collected during low water in 1990.

\begin{tabular}{lccccc}
\multicolumn{7}{c}{ Some activity ratios are also given } \\
\hline Sample & $\mathrm{U}$ & $\mathrm{T}$ & ${ }^{234} \mathrm{U} /{ }^{238} \mathrm{U}$ & ${ }^{230} \mathrm{Th} /{ }^{232} \mathrm{Th}$ & $\mathrm{Th} / \mathrm{U}$ \\
\hline O1 & $1.10 \pm 0.24$ & & $1.2 \pm 0.3$ & & \\
O2 & $1.08 \pm 0.13$ & $0.07 \pm 0.04$ & $1.27 \pm 0.14$ & $7 \pm 4$ & $0.06 \pm 0.04$ \\
O3 & $2.03 \pm 0.24$ & $0.11 \pm 0.05$ & $1.39 \pm 0.17$ & $9 \pm 4$ & $0.05 \pm 0.03$ \\
O4 & $86 \pm 10$ & $116 \pm 6$ & $0.98 \pm 0.05$ & $5.28 \pm 0.13$ & $1.35 \pm 0.17$ \\
O5 & $25.3 \pm 1.3$ & $31 \pm 3$ & $1.00 \pm 0.07$ & $6.1 \pm 0.7$ & $1.22 \pm 0.13$ \\
O6 & $13.4 \pm 1.5$ & $0.052 \pm 0.024$ & $1.07 \pm 0.17$ & $2.4 \pm 1.4$ & $(3.9 \pm 1.8) \times 10^{-3}$ \\
O7 & $19.1 \pm 1.7$ & & $1.06 \pm 0.06$ & & \\
\hline
\end{tabular}

values which are much higher than those previously found for suspended matter samples collected from other rivers. Indeed, Moore (1967) has measured U concentrations in Amazon and Mississippi rivers ranging from 1.8 to $2.4 \mu \mathrm{g} / \mathrm{g}$. On the other hand, $\mathrm{Th}$ concentrations in these rivers range from some 8 to $10 \mu \mathrm{g} / \mathrm{g}$ (Moore, 1967). In some japanese rivers Th concentrations range from some 2.2 to $6.7 \mu \mathrm{g} / \mathrm{g}$ (Miyake et al., 1973). Thus, it seems clear that stations $\mathrm{O} 4$ and $\mathrm{O}$, close to the fertilizer complex, are affected by the waste disposal from it.

In the case of the high water samples, the distribution of $\mathbf{U}$ and $\mathrm{Th}$ is different. The maximum Th concentration is $0.7 \mu \mathrm{g} / \mathrm{g}$ and there is a general homogenization of concentration levels, which may be due to the tidal mixing and to the input of non-contaminated suspended matter from the sea. On the other hand, $U$ concentrations are also lower than during low water, although there is still an important peak in station O5, which is close to the fertilizer complex. This effect was already observed for ${ }^{226} \mathrm{Ra}$ (Periáñez et al., 1994). It is interesting to note that the contamination is very localized around the fertilizer complex. However, some U contamination seems to affect all the studied area downstream the complex during low water.

In general, ${ }^{234} \mathrm{U} /{ }^{238} \mathrm{U}$ activity ratios are compatible with the existence of secular equilibrium in those samples in which high $U$ concentrations have been detected. This is not a typical feature for rivers, but it is typical of the minerals used for fertilizer production (Martínez-Aguirre et al., 1994). The secular equilibrium found in the Odiel river suggests an external origin for the suspended matter particles, probably from the fertilizer complex.

The ${ }^{230} \mathrm{Th} /{ }^{232} \mathrm{Th}$ activity ratios are $>1$ all along the river for both sets of samples. This reveals the high contamination of the river by members of the ${ }^{238} \mathrm{U}$ radioactive chain.

The existence of an external source of activity is confirmed by the $\mathrm{Th} / \mathrm{U}$ mass ratio. As $\mathrm{U}$ is largely more soluble than $T h$, it is often found in deficient with respect to $T h$ in the solid surface environment. Thus, suspended matter in unperturbed rivers usually have $\mathrm{Th} / \mathrm{U}$ mass ratios above unity. This is not the case with the Odiel river suspended particles. It can be seen in Tables 1 and 2 that, with the exception of samples $\mathrm{O} 4$ and $\mathrm{O} 5$ at low water, the $\mathrm{Th} / \mathrm{U}$ mass ratios are below unity. This reveals the existence of a external source of $U$ contaminated particles to the river. The exceptions are samples $\mathrm{O} 4$ and $\mathrm{O} 5$ which show $\mathrm{Th} / \mathrm{U}$ mass ratios above unity, typical of unperturbed rivers suspended particles. However, these samples being the most contaminated, the ratios should be related to the contaminants.

Tables 3 and 4 present the results for the low and high water samples, respectively, collected in 1991. The behaviour of Th is similar to that of the 1990 sampling campaign. There is a concentration peak in station $\mathrm{O5}$, close to the fertilizer complex, during low water and a very homogeneous concentration profile during high water. Nevertheless, there is a significant difference. The concentration levels, including that of the peak in $\mathrm{O5}$, are similar to those found in unperturbed rivers (Moore, 1967; Miyake et al., 1973). Nevertheless, the presence of $T h$ contaminated particles is clear since the Th concentration at station O5, during low water, is some four times larger than in the surroundings.

The case of $U$ is different, there are high concentration levels during both high and low water all along the river. Now the contamination is not reduced in the area close to the fertilizer complex, but extends from $\mathrm{O} 2$ to $\mathrm{O} 7$. This could be a seasonal effect. During the 1990 sampling campaign (summer, dry season) the water salinity was about four times higher than during the 1991 sampling campaign (winter, wet season), see Periáñez (1995). On the other hand, the water temperatures were $27.5 \pm 1.2$ and $15.0 \pm 0.8^{\circ} \mathrm{C}$ during the sampling campaigns of

Table 2. Concentrations of $\mathrm{U}$ and $\mathrm{Th}$ in $\mu \mathrm{g} / \mathrm{g}$ for the suspended matter samples collected during high water in 1990 . Some activity ratios are also given

\begin{tabular}{lccccc}
\hline Sample & $\mathrm{U}$ & $\mathrm{Th}$ & ${ }^{234} \mathrm{U} /{ }^{238} \mathrm{U}$ & ${ }^{230} \mathrm{Th} /{ }^{232} \mathrm{Th}$ & $\mathrm{Th} / \mathrm{U}$ \\
\hline O1 & $1.10 \pm 0.24$ & & $1.2 \pm 0.3$ & & \\
O2 & $3.9 \pm 0.5$ & $0.12 \pm 0.07$ & $1.12 \pm 0.16$ & $13 \pm 8$ & $0.031 \pm 0.018$ \\
O3 & $2.8 \pm 0.3$ & $0.19 \pm 0.07$ & $1.09 \pm 1.10$ & $3.2 \pm 1.4$ & $0.07 \pm 0.03$ \\
O4 & $9.0 \pm 1.0$ & $0.27 \pm 0.13$ & $1.24 \pm 0.10$ & $17 \pm 9$ & $0.030 \pm 0.015$ \\
O5 & $69 \pm 3$ & & $1.04 \pm 0.07$ & & \\
O6 & $1.6 \pm 0.4$ & $0.06 \pm 0.04$ & $0.9 \pm 0.3$ & $8 \pm 5$ & $0.04 \pm 0.03$ \\
O7 & $2.4 \pm 0.4$ & $0.7 \pm 0.2$ & $0.91 \pm 0.17$ & $5.1 \pm 1.9$ & $0.29 \pm 0.10$ \\
\hline
\end{tabular}


Table 3. Concentrations of $\mathrm{U}$ and $\mathrm{Th}$ in $\mu \mathrm{g} / \mathrm{g}$ for the suspended matter samples collected during low water in 1991. Some activity ratios are also given

\begin{tabular}{lccccc}
\hline Sample & $\mathrm{U}$ & $\mathrm{Th}$ & ${ }^{234} \mathrm{U} /{ }^{238} \mathrm{U}$ & ${ }^{230} \mathrm{Th} /{ }^{232} \mathrm{Th}$ & Th/U \\
\hline O1 & $1.55 \pm 0.19$ & $0.58 \pm 0.17$ & $1.67 \pm 0.18$ & $2.1 \pm 0.7$ & $0.37 \pm 0.12$ \\
O2 & $11.2 \pm 1.1$ & $0.09 \pm 0.06$ & $1.24 \pm 0.09$ & $27 \pm 19$ & $(8 \pm 5) \times 10^{-3}$ \\
O3 & $8.7 \pm 1.5$ & $0.07 \pm 0.04$ & $1.06 \pm 0.19$ & $8 \pm 5$ & $(8 \pm 5) \times 10^{-3}$ \\
O4 & $27.9 \pm 2.7$ & $0.34 \pm 0.15$ & $1.05 \pm 0.07$ & $9 \pm 4$ & $(2.8 \pm 1.3) \times 10^{-3}$ \\
O5 & $30 \pm 3$ & $11.3 \pm 0.9$ & $1.12 \pm 0.09$ & $5.8 \pm 0.4$ & $0.38 \pm 0.05$ \\
O6 & $48 \pm 6$ & $2.6 \pm 0.5$ & $1.13 \pm 0.09$ & $4.6 \pm 1.0$ & $0.054 \pm 0.012$ \\
O7 & $31 \pm 4$ & $2.1 \pm 0.6$ & $1.17 \pm 0.11$ & $2.3 \pm 0.8$ & $0.070 \pm 0.021$ \\
\hline
\end{tabular}

1990 and 1991 respectively. It is well known that an increase of salinity leads to dissolution of cations from suspended matter. This effect has been found for ${ }^{226} \mathrm{Ra}$ in, for instance, the Pee Dee river (Elsinger and Moore, 1980) and the Odiel river (Periáñez et al., 1994) and for ${ }^{238} \mathrm{U}$ in some laboratory experiments carried out by Bird and Evenden (1994). On the other hand, an increase of water temperature leads to a faster dissolution of ${ }^{238} \mathrm{U}$ from suspended matter (Ames et al., 1983). Thus, during the 1990 sampling campaign the $U$ may have dissolved rapidly while during the 1991 campaign it remained fixed to solid particles for a longer time.

Again, the ${ }^{234} \mathrm{U} /{ }^{238} \mathrm{U}$ ratios are in general compatible with secular equilibrium in the part of the river close to the complex. The ${ }^{230} \mathrm{Th} /{ }^{232} \mathrm{Th}$ ratios are again larger than unity, which shows a high contamination by members of the ${ }^{238} \mathrm{U}$ chain. Finally, the Th/U mass ratios are much below unity, which confirms the existence of an external source of activity.

Some distribution coefficients for ${ }^{238} \mathrm{U},{ }^{232} \mathrm{Th}$ and ${ }^{230} \mathrm{Th}$ are presented in Table 5. The activities of $U$ and Th isotopes in the liquid phase have been obtained from Periáñez (1995). In the case of ${ }^{238} \mathrm{U}$, our results are in agreement with the values found in literature. Indeed, IAEA (1985) showed that $K_{\mathrm{d}}$ for $\mathrm{U}$ in coastal waters can range from $0.2 \times 10^{3}$ to $5 \times 10^{3} \mathrm{~kg} / \mathrm{kg}$. The $K_{\mathrm{d}} \mathrm{s}$ are very similar for both Th-isotopes, suggesting that they are distributed between water and suspended matter in the same way. However, values below the range of variation which can be seen in the literature have been obtained. IAEA (1985) indicate that $K_{\mathrm{d}}$ for Th can range from $500 \times 10^{3}$ to $10,000 \times 10^{3} \mathrm{~kg} / \mathrm{kg}$. Nevertheless, a clear conclusion from these results is the large $K_{d}$ variation between different sampling points (up to two orders of magnitude). This variation comes from the $K_{\mathrm{d}}$ definition itself: it assumes an equilibrium situation for the exchanges between solid and liquid phases. This situation is not always achieved when an in situ measurement of $K_{\mathrm{d}}$ is made, especially in sites where the input into the system is changing with time (man made pollution). Thus, when a $K_{d}$ measurement is carried out, an extensive determination of the sampling conditions (salinity, temperature, $\mathrm{pH}$...) should be made in order to be able to interpret the result. It is probable that the equilibrium conditions can not easily be reached in nature. Thus, laboratory experiments and mathematical simulations are important tools which can help to understand the mechanisms of distribution of radioactivity in aquatic environments. This work has been successfully carried out in our group in the case of ${ }^{226} \mathrm{Ra}$ (Periáñez et al., 1996a,b).

\section{Conclusions}

The presence of significant concentrations of $U$ and $\mathrm{Th}$ in suspended matter samples collected from the Odiel river can be attributed to waste disposal

Table 4. Concentrations of $\mathrm{U}$ and $\mathrm{Th}$ in $\mu \mathrm{g} / \mathrm{g}$ for the suspended matter samples collected during high water in 1991. Some activity ratios are also given

\begin{tabular}{lccccc}
\hline Sample & $\mathrm{U}$ & $\mathrm{Th}$ & ${ }^{234} \mathrm{U} /{ }^{238} \mathrm{U}$ & ${ }^{230} \mathrm{Th} /{ }^{232} \mathrm{Th}$ & $\mathrm{Th} / \mathrm{U}$ \\
\hline O1 & $1.55 \pm 0.19$ & $0.58 \pm 0.17$ & $1.67 \pm 0.18$ & $2.1 \pm 0.7$ & $0.37 \pm 0.12$ \\
O2 & $63 \pm 5$ & $0.8 \pm 0.3$ & $1.196 \pm 0.024$ & $4.0 \pm 1.6$ & $0.013 \pm 0.005$ \\
O3 & $31 \pm 3$ & $0.41 \pm 0.19$ & $1.32 \pm 0.09$ & $4.7 \pm 2.3$ & $0.13 \pm 0.006$ \\
O4 & $119 \pm 10$ & $0.46 \pm 0.17$ & $1.071 \pm 0.013$ & $2.2 \pm 0.9$ & $(3.9 \pm 1.5) \times 10^{-3}$ \\
O5 & $94 \pm 8$ & $0.30 \pm 0.11$ & $1.115 \pm 0.022$ & $5.7 \pm 2.2$ & $(3.2 \pm 1.2) \times 10^{-3}$ \\
O6 & $33 \pm 3$ & $0.13 \pm 0.05$ & & $1.5 \pm 0.7$ & $0.010 \pm 0.005$ \\
O7 & $0.33 \pm 0.17$ & $1.27 \pm 0.06$ & $3.6 \pm 2.0$ & \\
\hline
\end{tabular}

Table 5. Distribution coefficients $(\mathrm{kg} / \mathrm{kg})$ for the 1990 low water samples

\begin{tabular}{|c|c|c|c|}
\hline Sample & ${ }^{238} \mathrm{U}$ & ${ }^{232} \mathrm{Th}$ & ${ }^{230} \mathrm{Th}$ \\
\hline $\begin{array}{l}\text { O1 } \\
\text { O2 } \\
\text { O3 } \\
\text { O4 } \\
\text { O5 } \\
\text { O6 } \\
\text { O7 }\end{array}$ & $\begin{array}{l}(0.15 \pm 0.3) \times 10^{3} \\
(0.38 \pm 0.05) \times 10^{3} \\
(0.91 \pm 0.12) \times 10^{3} \\
(12.5 \pm 1.6) \times 10^{3} \\
(4.8 \pm 0.4) \times 10^{3} \\
(3.0 \pm 0.4) \times 10^{3} \\
(3.8 \pm 0.4) \times 10^{3}\end{array}$ & $\begin{array}{c}(0.7 \pm 0.4) \times 10^{3} \\
(0.7 \pm 0.3) \times 10^{3} \\
(13.8 \pm 1.8) \times 10^{3} \\
(53 \pm 18) \times 10^{3} \\
(0.2 \pm 0.1) \times 10^{3}\end{array}$ & $\begin{array}{c}(0.59 \pm 0.17) \times 10^{3} \\
(0.91 \pm 0.17) \times 10^{3} \\
(13.3 \pm 1.6) \times 10^{3} \\
(30 \pm 4) \times 10^{3} \\
(0.07 \pm 0.02) \times 10^{3}\end{array}$ \\
\hline
\end{tabular}


from a phosphate fertilizer complex located close to the river. Tides and seasons (through salinity and temperature) affect the distribution of $\mathrm{U}$ and $\mathrm{Th}$ along the estuary. Some activity ratios have also been investigated, which have confirmed the external origin of the contaminated suspended matter particles. The $K_{\mathrm{d}}$ for U- and Th-isotopes has been calculated. The results show important variations from one sampling station to another, which are due to the fact that equilibrium conditions which are necessary for a correct $K_{d}$ calculation are not easily achieved in Nature.

Acknowledgement-This work was partially supported by ENRESA.

\section{References}

Ames L. L., Mc-Garraw J. E., Walker B. A. and Salter P. F. (1983) $U$ and $R a$ sorption on amorphous ferric oxyhydroxide. Chem. Geol. 40, 135-148.

Bird G. A. and Evenden W. G. (1994) Effect of sediment type, temperature and colloids on the transfer of radionuclides from water to sediment. $J$. Environ. Radioact. 22, 219-242.

Elsinger R. J. and Moore W. S. (1980) ${ }^{226}$ Ra behaviour in the Pee Dee river, Winyah bay. Planet. Sci. Lett. 48, 239-249.

IAEA (1985) Sediment $K_{\mathrm{d}}$ and concentration factors for radionuclides in the marine environment. Technical Reports Series 247. IAEA, Vienna.
Martínez-Aguirre A. (1991) Radioactividad natural en diversos compartimentos naturales de Andalucía. Ph. D. Thesis, Universidad de Sevilla (in Spanish).

Martínez-Aguirre A., García-León $\mathbf{M}$. and Ivanovich $\mathbf{M}$. (1994) $\mathrm{U}$ and $\mathrm{Th}$ distribution in solution and suspended matter from rivers affected by the phosphate rock processing in southwestern Spain. Nucl. Instr. Meth. A339, 287-293.

Miyake Y., Sugimura Y. and Yasujima T. (1973) Thorium isotope content in river water in Japan. Papers Meteor. Geophys. 24, 67-73.

Moore W. S. (1967) Amazon and Mississippi river concentrations of uranium, thorium and radium isotopes. Earth Planet. Sci. Lett. 2, 231-234.

Periáñez R. (1995) Un modelo matemático para la simulación de la dispersión de radionúclidos no conservativos en un sistema estuario. Aplicación de a la ría de Huelva. Ph. D. Thesis, Universidad de Sevilla (in Spanish).

Periáñez R. and García-León M. (1993) Ra-isotopes around a phosphate fertilizer complex in an estuarine system at the southwest of Spain. J. Radioanal. Nucl. Chem. Artic. $172,71-79$.

Periáñez R., García-León M. and Abril J. M. (1994) Radium isotopes in suspended matter in an estuarine system in the southwest of Spain. $J$. Radioanal. Nucl. Chem. Artic. 183, 395-407.

Periáñez R., Abril J. M. and Garcia-León M. (1996a) Modelling the dispersion of non-conservative radionuclides in tidal waters. Part 1: conceptual and mathematical model. J. Environ. Radioact. 31, 127-142.

Periáñez R., Abril J. M. and García-León M. (1996a) Modelling the dispersion of non-conservative radionuclides in tidal waters. Part 2: application to ${ }^{226} \mathrm{Ra}$ dispersion in an estuarine system. $J$. Environ. Radioact. 31, 253-272. 